CHAPTER SIX

\title{
MAKING A RELIGIOUS GENDER ORDER
}

One is not born a woman, but rather becomes one. -Simone de Beauvoir 1989 [1949], 1:92

The young generation of Muslims born in European societies frequently makes a distinction between the traditional Islam of their parents and a global, pure Islam detached from national traditions and ethnic bonds. Few researchers have explored the effect of the distinction between culture and religion on young people's understanding and performance of gender relations and on their ethnic identification. As chapter 4 explored, distinguishing between tradition, or culture, and religion is an effort to practice a so-called universal, pure Islam. The focus in this chapter is on how the continuous efforts to disconnect tradition from religion shape how Muslim youth in Europe construct their own gender identities and how they identify with their parents' ethnic or national $\operatorname{group}(\mathrm{s})$.

MJD meetings cultivate a religious gender order whose meanings are situational, shaping a religious gendered habitus. Habitus is about the incorporation or instruction of the body vis-à-vis moral and social values considered proper within the social field, or class, in which one is socially situated (Bourdieu 1990; 2004 [1977]). Thinking about gendered subjectivity through the idea of habitus is fruitful, as gender is performed through embodied acts and dispositions. This chapter will first discuss how the young women learn to "make gender" (Ortner 1996) religiously. I demonstrate the ways in which a religiously defined gender order is constructed and contested within a framework in which a distinction is drawn between culture and religion. What gender norms and ideals are these youths subjected to in their identification as Muslim women? How do they respond to these ideals and discourses? Second, I discuss whether the religious discourse taught in MJD and its religious gender order, in relation to which they form their Self, can increase the emancipation of women. What scope of action is available within MJD's structure of values for women to contest and transform the religiously defined gender order? 


\section{Making Gender through Religion}

Gender is socially and culturally constructed, and always acquired (Butler 1990). Similar to ethnicity and class, gender is an embodied practice (Bourdieu 1990; 2004 [1977]). Gender marks space and agency. Being a Muslim youth is always a gendered identification. Most religions have specific norms on dress, food, or body comportment that are defined according to a person's sex and that dictate how men and women should ideally interrelate. ${ }^{1}$ The Islamic mode of piety or moral conduct is genderdefined in the sense that the ideals of being pious and how to be a Good Muslim are defined differently for women and men. However, the conceptualization of Muslim women's roles that are considered religiously correct also varies across time and societies, as well as between classes and generations within the same society (El-Solh and Mabro 1994). Changes in context and education, including religious instruction, can change perceptions of social roles and modify an individual's available bases for negotiation and creativity within a specific social field.

Research on young migrant women commonly argues that the process of growing up is structured from a traditional, gender-specific role attribution taught in the family. ${ }^{2}$ This neglects how a gendered socialization can also take form within religious groups and organizations, such as the MJD. Gendered expectations, obligations, and rights as suggested by religious norms and traditions are taught in the family, as well as in Koran schools, mosques, and religious organizations, through the Internet, and by peers. The youths in this study also encounter a variety of discursively constructed gendered expectations from their families, faith communities, schools, and non-Muslim and Muslim peers. The process of learning and embodying what is considered correct female behavior, character, and dress comportment in a specific social field takes place in differentsometimes conflicting and sometimes coherent-social spaces such as MJD, school, and in the family. In this chapter, I therefore focus on the gender order produced in the youths' faith community, MJD. For these youths, familiarizing themselves with a religious gender order through which the individual is subjected to a gendered religious habitus is also part of the process of crafting a religious Self.

1 The moral conduct in Christianity and Judaism is also gender-defined. This does not only apply to religion. Different societies define men and women differently (Yanagisako and Collier 1987) or, as Butler states, gender is "a variable cultural accomplishment" (Butler 1990, 142).

2 See Lübcke (2007). 
The process through which a gender habitus is produced compels a complex social process of education (or Bildung). An essential feature of this process is how social relations change and mark bodily behavior, since habitus is both produced and articulated through gestures, ways of walking and dressing, and manners (Bourdieu 1990, 2004 [1977]). ${ }^{3}$ Learning to dress, move, and greet is political in the sense that through this process one learns a tacit understanding of legitimate ways to (re)present the body to others and the Self. As Moi argues: "The body — and its apparel such as clothing, gesture, make-up, and so on-becomes a kind of constant reminder (un pense-bête) of sociosexual power relations" (Moi 1991, 1031). The crafting of a religious Self that is de-ethnicized and defined by a religious gender order within a religious youth culture is a continuous social process in which the individual actor situates the Self vis-à-vis a gender order defined by the group. That said, the youths do not respond homogeneously to the particular gender order or dispositions; rather, they respond through creative appropriation, as illustrated in chapter $5^{4}$

Much of the knowledge that the young people are expected to internalize needs to remain conscious, and not tacit, in order for the practice of this knowledge to remain religiously correct (as discussed in chapter 4). Nonetheless, the concept of habitus remains appropriate to our understanding of the social processes of the youth, since the social production of bodies within this social field also involves basic activities like how one moves and how to greet others. These, and similar, bodily behaviors are ultimately supposed to become part of the unconscious religious daily comportment. ${ }^{5}$ I have already discussed how corrections, fear of a bad reputation, and feelings of discomfort can have a disciplinary effect and also promote group attachment, or feelings of belonging to this faith

3 At the same time, Bourdieu stresses that the individual contributes to the reproduction of existing social structures through bodily behavior (Bourdieu 1990, 2004 [1977]). Moi (1991) argues that producing the social body also produces a political body, or an embodied politics, which points more in the direction of the possibility of changing social structures than Bourdieu's focus on their reproduction allows.

4 Yet, to the extent that the social fields develop isomorphic properties, including perceptions of exclusion and inclusion, and systems of change, the field becomes homologous (Bourdieu 1990).

5 Additionally, though much of the knowledge taught in this social field is not tacit and is expressly stated, as chapter 4 illustrated, there is also a series of unspoken and unarticulated rules about what can be said or perceived in this field. To some extent, then, the social field operates with censorship (Bourdieu 1984). As Moi points out: "Within the field, every discourse is euphemistic in the sense that it has to observe the correct forms, legislated by the field, or risk exclusion as nonsense (...)" (Moi 1991, 1022). Importantly, Bourdieu's concept of habitus has rightly been critiqued for not explaining how resistance takes a particular form or how that resistance is socio-historically possible (see LiPuma 1993). 
community. Here, I pay attention to how the youth are constructed by and subjected to specific religiously defined discourses taught in MJD, as well as to the impact that German views of Islam have on their gender identities. Simultaneously, I suggest that when the youth are making gender through religion, they also enact these discourses differently by accepting, resisting, or negotiating gender ideas and ideals. ${ }^{6}$

\section{The Virtuous Female Body}

Research suggests that women are more attracted to religious movements than men (Furseth and Repstad 2006; Walter and Davie 1998). MJD is no exception: two-thirds of the 600 official MJD members are women. According to one of the shura members, this gender ratio has proven to be constant and independent of the actual number of members. The weekly, gender-divided meetings also see more female than male attendees. Further, women seem to participate more actively than men in MJD religious events and in the administration of MJD events. I have not examined the reasons for this; one male shura member suggested that parents are enthusiastic about the idea that their daughters participate in a religious organization and that many young women feel that if they are involved in a Muslim organization, their parent's social surveillance of their leisure activities will diminish.

The process of crafting the Self as a young Muslim woman within the religious space of MJD involves perfecting knowledge of religious norms about dress, body comportment, and the roles and duties of a Muslim woman. In sum, it means making a (new) religious gendered habitus. For example, presentations and discussions at MJD meetings refer to the idea that Muslim women are the primary Islamic teachers for their children. As the mother will be the first teacher for the child, knowledge of and insight into Islam becomes a duty in order to be a good Muslim mother. Further, the wives of Muhammad are viewed as role models for the Muslim woman, which is an identity that is framed in family metaphors such as wife, sister, mother, and daughter.

\footnotetext{
${ }^{6}$ I use Ortner's concept of "making gender" (1996) in order to understand the gender formation among the youth in MJD because it incorporates two relevant ideas: on the one hand, the idea of the subject as constructed by and subjected to the cultural and historical discourses that people have to relate to in their everyday life. Here, the question of what kind of identities and subject positions are constructed within a particular cultural, ideological, and discursive formation is the main focus of attention. On the other hand, it emphasizes the ethnographic actor's point of view, paying attention to how people enact, resist, and negotiate the world as given, and how this results in their actually making their life-world.
} 
Through the MJD weekly presentations, the youth become familiar with these historical women and their characters, activities, and roles in the first Islamic society. Overall, the perception of gender in MJD is projected through familiarizing its participants with the ideal Muslim Woman as provided by the teachings of Islam and in relation to the Muslim Man, who I discuss further below. In this process, their understanding of gender is distinguished from one, the general (mis)understanding of women in Islam by the German, non-Muslim majority; two, their perception of the incorrect Muslim woman; and three, their understanding of the nonMuslim woman as constructed by the Muslim youth's understanding of the German heterosexual matrix.

First, the youth differentiated their religiously defined gender order from the more common media stereotypes of women in Islam. For example, during one MJD meeting, the young women discussed how the media promotes stereotypical views in which Muslim women are seen as without rights and as not emancipated. This perception was then disproved by pointing to how women are supposed to be treated in Islam. The youth believed that such stereotypes were both a consequence of misinformation among journalists and people in general about the role of women in Islam, and of the fact that people who are identified (by others, though not necessarily by themselves) as Muslims do not always behave according to Islam. Although they recognized that women are not always treated according to the principle of complementary genders in everyday life, most of the young women believed that there are ways of strengthening women's situation within Islam. By referring to the role of the wives of Muhammad and to prominent religious figures, they pointed to the important position of women in Islam historically. The young Muslims also made socio-historical comparisons, such as when they stated that Islam introduced rights for women that were granted only much later to Christian, European women. There was a general belief among the youth that if both women and men would only correctly follow the rights and obligations stipulated in Islam, such correct behavior would show that women are highly regarded in Islam. They believed that behaving according to Islamic teachings would assist in changing negative stereotypes of women in Islam, and consequently, people would be more likely to convert or at least seek more knowledge of Islam. ${ }^{7}$

7 As discussed in chapter 4, the potential consequence of this perception leads to a high pressure on women to conform their public behavior to gender norms, from herself, peers, and significant others. 
Second, the youth frequently drew a distinction between themselves and other veiled young people who they considered to not behave in a correct Islamic manner. The young women differentiated between traditional gender roles (often viewed in ethnic terms, such as Turkish), which were practiced among what the youth viewed as less actively religious people, and the gender roles of de-ethnicized, religiously oriented people like themselves. The youth regularly discussed other veiled women who dressed sexily at religious youth activities (such as those organized by MJD), smoked, or in other ways did not respect Islamic gender rules; for example, by mingling improperly with men in public. Through such comparisons and distinctions, the youth presented themselves with an image of how they should or should not behave in public.

Third, the youth highlighted differences between themselves and what they viewed as the typical German woman. This took place through discussions about how German women dress (particularly during the summer), through critiquing commercials which (mis)use female bodies, and by making distinctions between the ideal gender relation between men and women in Islam versus in Western societies. These discussions fostered stereotypes of German women that are reciprocal to those which the majority German society holds about Muslim women, as the young people considered the former to be oppressed by the commercialization of their sexuality. As I discussed in chapter 3 , when Westerners stereotype women in Islam as traditional and submissive, this can contribute to the construction of Western women as modern and liberated. I have found that young Muslim women also stereotype the Western woman as commercialized in order to bolster their construction of women's position in Islam as ideal and emancipated. The following event can illustrate how such processes, which resemble Occidentalism, take place:

One cold winter evening, as I was walking with a group of MJD participants after visiting the Christmas market at the Schlossplatz, a young woman with a short skirt and high-heeled shoes passed us on the way to Alexanderplatz. When she was out of sight, Helene (24), a German convert, commented to the group: "I am so glad I don't have to dress like that," referring to the woman's thin and sexy clothes. A discussion followed about how German women feel the need to dress revealingly to attract attention, which not only discredits their bodies but is even a health risk.

Women in Islam were considered better off than German women, as the former do not have to focus on their outer appearance the whole time. Many of the Muslim youth considered the German idea of emancipation to be merely about free sex and about wearing either revealing or 
unfeminine clothing. The latter stereotype refers to what many considered to be the typical feminist ideal in Germany; the so-called "Emmas." 8 The German feminists Emmas are Othered by the young women, as the former are seen to undermine their own femininity through their bodily performances, such as not shaving under their arms.

As discussed in chapter 3 , the process of comparing stereotypes of "us" and "them" involves making contrasts in terms of status and hierarchy and allows differences within social groups, including power differences between women and men, to be concealed and controlled (Nader 1989). The comparison contributes to social control within the group by producing the group's model of womanhood as ideal, in relation to which the other group's model becomes inferior. In both cases, the idealized stereotype of the Self, which is compared with a negative stereotype of the Other, obscures important power distinctions between women and men within these social structures.

\section{Ideals of Gender Relations: Complementarity versus Equality}

Through communication with classmates at school, through watching German and American blockbusters, and through being exposed to public advertisements and the media, the youth experienced or perceived what many of them considered to be Western gender-equality ideals, which they saw as distinctive from the Islamic gender order. The Western feminist notion of equality was interpreted to mean a specific form of gender equality in which the genders are seen as having equal capacities and as therefore being entitled to identical opportunities and rights. Such a starting point is not compatible with how the MJD youth viewed gender relations. Rather, they believed that it is God's will for men and women to be different, and consequently, they believed that space and status must

8 Founded in 1977, the first German women's magazine, EMMA, is written "by women, for women" and is tied to the name and image of Alice Schwarzer, the most prominent feminist in Germany. The name Emma calls to mind the word emancipation in Germany. The magazine has since its initiation been a popular forum for discussing abortion, equal rights, pornography, and prostitution. The topics it covers have changed from a focus on women's rights and women's status in the Catholic Church in the 1970s, to issues like eating disorders, genital mutilation, and Islam's treatment of women (Source: Deutsche Welle 2007). Today EMMA is almost synonymous with feminism in Germany (Eigler and Kord 1997, 572). In recent years, Alice Schwarzer has also become known for her critical statements about political Islamism and the position of women in Islam. She favors a headscarf ban in schools or other public settings, as she considers the headscarf a symbol of oppression. She warns of a "creeping Islamization" of Europe, which she argues will lead to an erosion of Human Rights and women's rights (ibid.). 
be provided for the realization of specifically female and male potentials and values.

Gender relations at the meetings and in discussions among the youth are explained in terms of proper roles for women and men. These are determined by religious rules and norms, and an effort is made to distinguish these from cultural norms and ethnic or national traditional views of gender. At the same time, the youth took a clear stance against the German ideal of women's emancipation, which most of them found to be focused on sex. Rather than emphasizing equality or sameness, which is the focus of Western feminism, MJD encourages young Muslims to view each gender as complementing the other: women and men are different, and these differences should be given space and lived out in everyday life. The Islamic ideal of complementary genders, of what is permitted and correct for a Muslim woman both in private and in public, was considered different and better than the German emancipation movements that focus on the perception of women and men as equal because they are the same. The youth distanced themselves from what they perceived to be a German interpretation of gender equality and instead emphasized an Islamic notion of gender differentiation and gender order. For example, while on the subway on our way to a picnic, Ines told me:

I have to do something the whole time. I can't sit and do nothing; I would work even for little money, difficult things even, just 'cause I cannot sit like that and get money from the social office, for example. (...) When I get married, in 10, 20 or 30 years, my husband can sit at home and I'll go to work. [She laughs.] No, with us, Muslims, it is like that, that the man should earn the money for the family and the woman can work if she likes, but she doesn't have to. They [non-Muslims] make such a fuss about it. That it is oppressing the woman. Like, what is it about that (situation) which is not emancipated? Isn't it nice, "nah," that we can just sit at home with our feet on the table and relax and don't have to work? I don't see where the problem is. Anyhow, my husband can sit at home and I'll have to work! No, he can work, but I will also work, in sha'a Allah (God willing).

Ines recognized that the idea that Muslim women do not necessarily have to work is viewed as not emancipatory. However, she found it incredulous that women's right to choose not to work is seen as evidence of oppression. Yet, although Ines insisted that the Islamic idea of womanhood in which a married woman is not obliged to work is unproblematic, at the same time she maintained that she personally wanted to work. In fact, young women's aspirations in the educational system were encouraged within MJD, where education is promoted as a religious imperative. In Islam, employment is considered a right but not a duty for women. 
During MJD meetings and discussions, the first wife of the Prophet Muhammad was used as an example: Khadija was a successful businesswoman who employed the Prophet to watch over her caravans.

Within MJD, higher education and employment become part of the project to deconstruct the idea of Muslim women as oppressed housewives. Working is also important to Muslim women in light of the negative stereotypes of Muslim women as not working because they have too many children, are prevented from working by their husbands, or because Muslim women are perceived to prefer to exploit the welfare state. Working while veiled is one way of communicating to German society that they, as Muslim women, can also have a career. ${ }^{9}$ Completing higher education and being employed in various occupations thus becomes a religious duty $\left(d u^{\prime} a\right)$. In other words, the working Muslim woman is promoted as one way to improve the negative stereotypes of Muslim women.

\section{Creating Gendered Religious Spaces}

The MJD events that bring men and women together are spaces in which youths gain skills in the correct interaction between Muslim men and women. In particular, the monthly meetings and the annual summer camp establish social spheres where men and women are supposed to follow a religious gender order, a process in which the religiously defined gender relations become central in shaping the youths' body-place relations. The following ethnographic description of traveling with MJD exemplifies this:

As we leave together on a bus, the brothers sit at the front, and the sisters sit at the back. In the middle, some seats are reserved for married couples who prefer to sit together. The female leaders are at the front, using the microphone to go through the schedule, tell jokes, or initiate games where the sisters compete against the brothers. In a similar way to religious meetings at some mosques (like DMK in Wedding), children are bringing messages or candies between the different gendered parts of the bus. When we stop to eat and pray, the prayer is conducted on a grass field next to a petrol station and is led by one of the brothers. The sisters pray behind the brothers, as is

9 In her ethnography on Muslim youth in Chicago, Schmidt (2004b, 73) points to a similar discussion on the rights and obligations of Muslim women to finish high school and to work after marriage. She situates the arguments of the youth in terms of the American notion of individualism. Although my data suggests that these Muslim youth in Germany are shaped by the German gender structure-for example, the encouragement for (West) German women to pursue a career-Islamic rather than secular discourses are used in MJD to endorse this lifestyle choice. 
religiously prescribed. Many women who cannot pray try to hide their absence, so that the brothers do not find out that they are menstruating.

Through practices like a gendered division of seating on the bus, there was an effort to organize and put spatial boundaries between the two genders. The annual MJD summer camps, a kind of "Halal summer camp," are organized with a view to upholding a religiously defined gender order, including gender-divided times for sport. Some of the seminars (e.g., "the role of women in marriage") are also geared specifically to women. During presentations at the three-day summer camp, women are seated on the left-hand side and men on the right-hand side. ${ }^{10}$ Controlling the gaze is another practice that contributes to the symbolic border between the genders. By referring to sura 24: 30 and 24: 31, the organizers discourage direct eye contact between the genders. ${ }^{11}$ However, this is mostly in principle, as in practice the leaders concentrate on issues like women not talking alone with a man or not staring at the men while they play sports. Still, contact across the gendered spheres does take place; for instance, through glances, taking pictures of brothers on the sly, and in short conversations. Indeed, these trips are also a way to get to know brothers who are potential marriage partners.

The practice of spatially ordering gender, as practiced on the bus, marks the Muslim organization as gendered. The clear rules, firm values, and marked spatial arrangements simultaneously differentiate between the genders and integrate the group as a whole. In this way MJD becomes a sometimes intuitive, sometimes structured, symbolic space for praxeological forms. At the same time that practices like greeting, manner, and body

10 Most mosques insist upon a seating plan where men sit in the front and women in the back, physically divided by a screen of some sort, or the men and women sit on different floors. Sitting in rows next to each other while on different sides of the room is considered too liberal by some Muslims and as too conservative by others.

11 These two suras are often referred to when it comes to dress code. There are some differences in the English translations of these suras. Sura 24: 30: "Say to the believing men that they should lower their gaze and guard their modesty: that will make for greater purity for them: And Allah is well acquainted with all that they do." Sura 24:31: "And say to the believing women that they should lower their gaze and guard their modesty; that they should not display their beauty and ornaments except what (must ordinarily) appear thereof; that they should draw their veils over their bosoms and not display their beauty except to their husbands, their fathers, their husbands' fathers, their sons, their husbands' sons, their brothers or their brothers' sons, or their sisters' sons, or their women, or the slaves whom their right hands possess, or male servants free of physical needs, or small children who have no sense of the shame of sex; and that they should not strike their feet in order to draw attention to their hidden ornaments. And Oye Believers! turn ye all together towards Allah, that ye may attain Bliss." From: http://www.islamicity.com/ mosque/QURAN/24.htm, accessed March 18, 2009. 


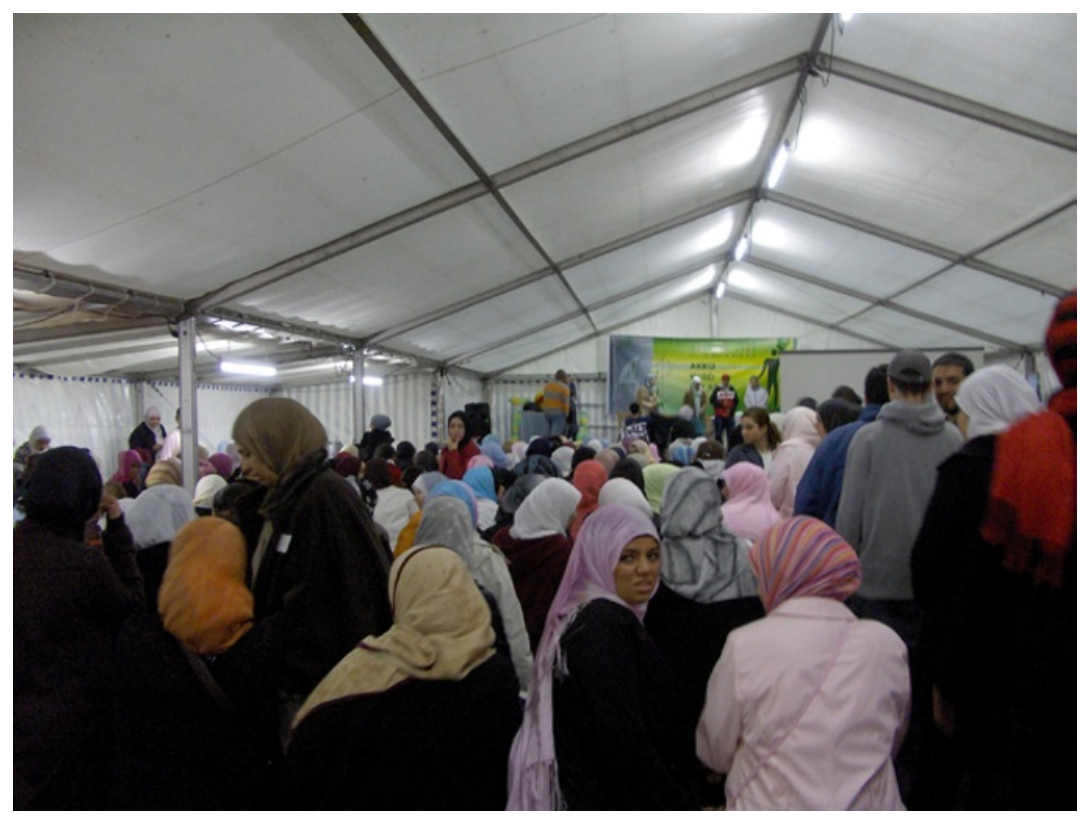

Figure 12. Inside the seminar tent at an MJD summer camp. Women sit on the left-hand side, men on the right-hand side. Photo: Synnøve Bendixsen.

management construct symbolic borders between the genders, they also create a feeling of belonging to a group or community.

At some MJD events, leaders and participants issued explicit guidelines and instructions for dress comportment:

When planning a picnic the forthcoming Sunday, one of the older leaders issued directions for the women's dress, saying: "And we will all wear the headscarf there. Remember that the brothers are with us. And I guess I don't have to tell you that we must dress properly. I think we all know what the limits are."

During the same weekly meeting, Fadwa (23) (the leader at that time) talked about the upcoming MJD summer camp:

There are going to be around 800 young Muslims there. Let us try to give a particularly good impression - in terms of dress - to look good. Think about how we will spend three to four days in a Muslim atmosphere and that we must also think about (how we present ourselves). It is also a chance to try to come further [religiously] with ourselves. At another meeting, we decided that for the next meeting we were not going to wear trousers, everyone was going to wear skirts. Not that trousers are not allowed, of course. And we did 
it. And the next time we decided that we were not going to wear make-up. [Some of the participants make unenthusiastic comments]. And some did not wear it for months after, though most have started again. The idea is to just little by little break away from some habits. This meeting is also a place where one can get used to wearing the headscarf, for example.

Through such speeches the gender roles, norms, and ideals within this Islamic faith community are identified and encouraged, which advances collectivization. In her speech, Fadwa encouraged specific ideals for the young women that they should strive to perform. The upcoming event was presented as a space where they could practice and change their habits to become proximate to the religious gendered ideals of body and dress comportment. Later, I discuss the different ways that the young women relate to these discursively constructed subject positions.

The constraints on or expectations related to women's clothing practices seem to be more articulated than those for men. For example:

At an MJD meeting, the leader told everyone to take care this year to bring along modest clothes to the upcoming three-day MJD summer camp. This was an explicit response to the fact that some youth had not brought Islamically correct clothes with them the previous year. Bringing modest clothes, she said, is not only so that they could get used to wearing these kinds of clothes and also to not wearing make-up, but also because "for the brothers it is haram to look at you like that, and do you want to cause this to your brother?"

Here, the women were partly given responsibility for the male participants' transgressions, which were seen as being caused by the women's clothing. The general symbolic elevation of women as bearers of the collective (see Yuval-Davis 1997) is a practice which is brought to the forefront in this example. ${ }^{12}$ One young woman asserted that the brothers should also be careful about what they wear:

During the three-day MJD summer camp, Naila (16) complained to her close friend and me that she also found it difficult to concentrate on her prayer when a handsome man is standing further up in the prayer lines wearing a tight t-shirt. Naila further reflected on how as a woman, she was always told to be careful in her dress comportment, while the brothers were not careful.

12 In so far that gender is central to the construction of collective identity, feminist social scientists point to how women often become symbols that mark the borders between social groups and categories, and that women come to signify a group or category's superiority (Moghadam 1994; Yuval-Davis 1997). 
Apart from Naila's comment, I rarely heard women discussing the correctness of young men's clothing in Berlin, though they often discussed the clothing of other women. However, I often heard negative comments about the incorrect behavior of (Muslim) Turkish or Arabic men in Berlin, including the fact that they would talk to unknown (veiled) women, drink, swear, and misuse Allah's name.

Although the above discussion illustrates how MJD offered clear instructions about clothing, correct dress comportment was also indirectly developed by participating in a specific atmosphere, something I felt in relation to my own body during the fieldwork. After a period of time, I started to make sure to cover up extensively when spending time with the young women. My desire not to emphasize difference made me more conscious of how I dressed during events and meetings with the youth. When I failed to do so, such as when too much of my chest was revealed, when my sleeves stopped just below my elbows, or my sweater did not cover my hips, I noticed that I felt uncomfortable. ${ }^{13}$ This feeling of being ill at ease was not related to any looks or comments (which rarely happened) but was more about being in an environment where everyone dressed in a particular way and where I felt that I did not fit in with my choice of clothing. I understand this as an indicator of the bodily practices (Asad 1997) and techniques that are part of the crafting of a specific subject.

\section{The Corrections}

I noticed that the youths regularly corrected each other when they were in public, such as approaching each other if their headscarves were out of order or asserting that a friend's clothing was too sexy. ${ }^{14}$ Such corrections of imperfect performances of conventions have the effect of controlling and integrating the individual subject and thus play an essential part in

13 The attention I started to pay towards my own dress comportment was a combination of trying to fit in and trying to make sure that particularly the older leaders of the group understood that I respected their way of comportment and that I did not intend to try to influence the younger participants with regard to dress. Interestingly, at the same time that some of the young women would tell me that "you are dressing more and more like a Muslim," another girl told me "if I was not a Muslim, I would dress the way you do," indirectly indicating that my dress did not pass as that of a Muslim despite my efforts to dress modestly.

14 For example, Dunya (25), a student from Austria visiting Berlin for one year, told me that she often received the comment "sister, you are wearing the headscarf wrong," as she would tie the knot behind her neck, leaving her neck visible. She found this effort to correct her veiling, sometimes also by (Muslim) strangers, annoying. 
the collectivization process. A social field has rules of inclusion and exclusion, as well as ideas of legitimate and illegitimate practices and discourses (Bourdieu 1994). Though much of the knowledge taught in this social field is not tacit, but rather articulated explicitly, there is also a series of unspoken and unarticulated rules for what can be said or is considered as legible in this field. To some extent, then, the social field operates with censorship (Bourdieu 1984). As Moi points out, "within the field, every discourse is euphemistic in the sense that it has to observe the correct forms, legislated by the field, or risk exclusion as nonsense" (Moi 1991, 1022). There are limits on the available choices and room for maneuver: in order to be accepted and included in the social field, the individual must operate within the borders as normatively defined by the nomos, namely the social rules that are of overall importance in a specific social field..$^{15}$

Moving between different social contexts, such as MJD, school, work, and family, the young women were exposed to and engaged with various gender orders. ${ }^{16}$ Consequently, the youth produced gender in relation to various social expectations. Furthermore, examining religious discourses on gender is insufficient when trying to understand how the young women produce gender, as this will not tell us how they react toward these discourses or how they experience the subject positions that they have to relate to in their everyday lives. Within the space of MJD, recommendations or expressions of expectations about dress comportment were not necessarily agreed upon or followed homogeneously. For example:

Naila (17) told me that during the three-day summer camp in 2004, she and her sister had been approached by a third participant who asked them to put on more decent clothes. Naila had responded that she didn't have any other clothing with her. In telling me the story, she also rhetorically asked why a young MJD participant should tell her how to dress "when not even my mother tells me?"

I understand Naila's reaction as partly a rejection of, or even resistance to, the call to conform, as she could have asked to borrow clothes to conform to what her peer considered religiously correct. It further illustrates that

15 I am not suggesting that someone who does not conform to dress and body behavior will be excluded from the faith community. However, a person who diverges extensively in her comportment and practices when participating in the faith community with which she identifies will meet continuous (often well-meaning) corrective comments and suggestions about how she should dress or behave.

16 Gender subjectivity is not a fixed or singular identity, but is based upon a sequence of subject positions presented by different discourses, of which some will be in conflict or in opposition internally (Moore 2007: 35). 
youth sometimes felt that MJD was a more restrictive socializing space than that of their family. Pressure from peers to conform to group orders can feel like a critique of the Self, which can be very effective as the practices are situated within a religiously defined discourse that the youths may find difficult to challenge.

That said, increased knowledge and confidence in the right to be selfreflective opens up space for individual negotiation or interpretations of these ideals. For example, during a wedding, Janna (19), who had become more concerned about her religious practice two years previously, told me:

You went to the seminar about marriage, right? [She refers to the seminar on women's and men's roles in marriage during the annual MJD summer camp in 2004, which was only for female participants]. And there was something I didn't agree with, but I didn't want to argue openly there. Like this idea that it is the duty of the women to [have intercourse] with the man if he wants. I don't think it is like that. I mean, Prophet Muhammad s'Allahu 'alayhe wa salam [Peace be upon him] was a perfect man, he would never have made the woman do something she didn't want to... if the woman says no, there is a reason for it. Also, I think that if a woman is cheating, it's 'cause the man is not giving her what she needs, it doesn't matter if it's only good sex.

As Prophet Muhammad is particularly relevant to the perception and construction of gender roles, having the knowledge and authority to define and narrate the different stories about the Prophet is a symbolic capital. Religious proficiency can provide a young MJD participant with status or recognition within the religious social field. Janna's account also illustrates internal disagreement over how to understand the duties and rights of women in Islam. Although she did not openly express her difference of opinion in the group, she seemed determined to follow her understanding of the marriage roles of women and men in her own life.

Internal divergences of belief about what is expected of a correct Muslim woman in the public sphere is further exemplified in the following discussion between Fahra (23) and a recently young German convert (19):

At a Saturday evening party in someone's home, Fahra tried to convince a German convert that wearing the scarf in front of her face (thus resembling a Niqab, the piece of cloth worn to cover a woman's face, sometimes also covering the eyes), or looking down when walking the streets in Kreuzberg during the evenings was not necessary — as long as she knew how to behave correctly in public. Fahra said: "You should not make it so hard on yourself. I, for example, know the limits. When I am here with you, I dance and sing and am crazy, but when I'm in the streets, outside, then I know how to behave. But it doesn't mean that one needs to walk with one's head down or not be outside at all or be completely covered." Fahra continued by referring 
to German converts who stare at the ground when walking in the street, which made her think, "Maschalla (what Allah wishes), I hope their husbands are treating them well." The German convert said that she never looked at anyone in the street, always looked down, and sometimes used a cover for her face. Fahra found this "extreme," "unnecessary," and even "unfortunate" because she believed that Muslim women who behave in this way send negative signals to non-Muslim society. To her, it was particularly problematic that a German convert behaved like this in public. Fahra said that she knew many Turkish families who made their daughters come straight home after school. She noted that "they are not allowed in the street, [the family] only think about honor and reputation — not about Islam. Their sons can do everything and their daughters nothing."

The disagreement about what is necessary and what is extreme exemplifies internal differences about what is meant by modesty. Fahra was trying to open up the social space for the German convert, who she believed was over-performing being a Muslim woman when in public. Fahra argued that Muslim women should not limit themselves; it would be enough to know how to behave, though Fahra did not really define what that meant. Quite joyful and outspoken during the private party, she assured us that she knew how to behave as a Good Muslim Woman in public. Fahra seemed to fear that what she considered the exaggerated performance of the German convert would not make the convert less visible in the public sphere. Rather, it would make her more visible to non-Muslims due to the negative views of veiled women. Furthermore, Fahra considered the stricter treatment of daughters compared to sons to be unrelated to Islam. I often heard the youth take a stance against their ethnic group and the group's practices. The youth saw their own increased knowledge of Islam as one way to alter what they viewed as the unequal treatment of young men and women by their parents' generation. ${ }^{17}$

Outside the social space of the faith community, the religious gender order seemed to be less actively pursued. For example, I noticed a difference in how some MJD participants dealt with Muslim brothers at MJD events and non-Muslim (male) classmates. Whereas some women did not shake hands with a brother, they seemed unconcerned about shaking hands with non-Muslim boys at school. On the one hand, this can be understood as moving between different social fields, where different role

17 I often heard youth discuss the double standards among parents with migrant backgrounds, in that daughters were treated much stricter than sons. The youth believed that if both the daughters and the family were behaving Islamically correctly — that is, following what the youth considered to be right and wrong according to Islam-the family would not enforce such strict surveillance. 
performances are emphasized or considered the correct practice. On the other hand, deciding to shake hands with a classmate can also be understood as an effort to not alienate non-Muslims from Islam and may be triggered by a fear of being seen as extreme. Clearly, most youths did not expect that non-Muslim men would know the rules for how to behave in a religiously correct manner toward Muslim women. Additionally, nonMuslim men were rarely considered potential marriage partners among these religious youth, which perhaps made it less important to keep up the religious gender order in that social situation.

In their daily lives, the women not only distinguished between Muslim and non-Muslim men, but also differentiated between religious and ethnic Muslim men. The separation that the youths constructed between culture and religion shaped not only the gender order but also has two further consequences in the women's lives - their relations to their ethnic social field and their marriage practices. I turn to these next.

\section{Finding a Suitable Husband}

Among the youth in Berlin, distinguishing between Islam and culture can ultimately facilitate their distancing themselves from negative stereotypes of Turks in the German media and public sphere. For example, when discussing issues like honor, shame, honor killings, and forced marriages, whether among themselves, with other Muslims, or with non-Muslims, the young people labelled these issues as un-Islamic and related to traditional practices. In discussions and when talking with friends, the women frequently referred to stereotypical images of Turkish or Arabic men as macho and not fulfilling their role as Muslim men. ${ }^{18}$ The following episode illustrates this:

Spending the night for Qiyam al-Layl ("standing at night," the voluntary night prayer), praying, and reading the Koran in a German-speaking mosque in Wedding, the youth chatted in between the official program. One of the women, Fatima (31), told me, "the [Turkish] woman is not allowed to go out [and do the same things as men]. The man can do everything, and the woman has to stay at home [in the evening]. The Turkish are machos, I know. I can say so, because I am Turkish. But it is not Islam [that makes them macho]. In Islam, women and men are equal. It is typical Mediterranean temperament, you know. The Spanish and the Italians are also macho.

18 Ewing (2008) presents an excellent discussion of the stigmatization of Muslim masculinity in European countries and its effect on men with Turkish backgrounds. 
But there are also advantages for the woman, you know. She can feel protected that way."

Later the same evening, the Muslim brothers, who were spending the night in a different area of the mosque, made dinner for the women. When they passed by the women's part of the house, which was attached to the mosque where the food was prepared, Noreen (16) told me, "that is how Islam is really; the men should do more than the women. It is just because they are not educated that women today do more than the men. You know, the Prophet Muhammad used to mend his own socks when he had time. In addition to being a statesman, religious (leader), and a good husband."

The latter comment must be seen as directed toward me, a non-Muslim woman who was often invited to convert to Islam. Especially at the beginning of my fieldwork, some of the young women overemphasized what they considered positive aspects of Islam in order to combat the negative stereotypes they thought I must have been exposed to. That said, the comment also relates to a clear distinction the women made between Turkish or Arabic men and men in Islam as defined by the religious gender order taught in MJD. During the weekly discussions, the Prophet Muhammad was often presented as a role model for any person who is striving to lead a correct religious life, and specifically as a role model for how a husband should treat his wife. Notably, the young women made a comparison between ideal images of religiously devoted Muslim men and stereotyped images of culturally oriented men.

The young women also differentiated between Muslims in Germany and Muslims in their parents' countries of origin. The following conversation among three 17-year-olds during a small friendship gathering illustrates this point:

Nawar said, "I am for sure not going to marry an Egyptian. Unless he is modern. That [he also does housework]." Naila agreed, "the men there, hey! They expect women to do everything for them, and with the attitude that 'that is Islam,' sort of. Like, I often saw men asking women to get them another cup of tea or something. Or that the woman is cleaning, lifting the sofa and such, while the guy is just sitting in the chair zapping through the television channels. Makes me crazy!" Somaya continued, "like, where in the Koran does it say that the women are supposed to be cleaning-women? That they are only for cooking, cleaning, and giving birth to children? They are really bad in Egypt and [the Middle East], not like here. Here, they are different." Naila was of the same mind, "the best Muslims are here! Like there, they kill, cheat, lie, and everything. I saw it so often. Like, at least the Muslims I know here are really better." The other girls agreed with her.

Here, the youth drew a sharp contrast between Muslim men in Egypt and in Germany. Nawar's emphasis on marrying a modern man exemplifies 
how the youth drew on ideas of what it means to be modern. In this context, being modern is not about being a Muslim or not, but about the man's attitude toward and treatment of his wife/ves. Nawar drew a distinction between Muslim men in Egypt, who were seen as traditional because they pursue gender rules provided by culture, and Muslim men in Germany, who were seen as modern because they adhere to gender rules as provided by Islam. ${ }^{19}$ Such rejection of culture and traditions as sources of authority establishes a hierarchical distinction between Muslims, namely between those who understand and perform their religion in a pure form and those who relate their faith to culture and tradition. A modern Muslim is someone who struggles for a non-cultural approach to Islam. Thus, to be modern is not necessarily related to Europe but to how Islam is practiced. A modern Muslim is someone who is self-reflexive, seeks to acquire knowledge of the pure Islam, and follows these rules and obligations in their life.

\section{Halal Dating}

"I didn't know MJD was this important to me!" one of the MJD youths exclaimed, referring to the large number of young Muslim men at the annual MJD summer camp. The youth often complained about how difficult it was to find a potential husband in Germany. MJD meetings, events, and trips became spaces where youth could meet devoted Muslims of the opposite sex. Often the youth found their future marriage partners within the organization. This is partly a consequence of MJD representing a space where there is a relative proximity of participants of the other sex at events but also because there is a likelihood of other participants sharing similar views about religious beliefs, values, and practices, which in turn enables a cultural and religious homogeneity within a relationship. ${ }^{20}$

Marriage is a central component in regulating sexuality and gender relations in the Islamic tradition. ${ }^{21}$ Marriage can also be a particular

19 In contrast, Özyürek (2009) argues that the converted German Muslims in Berlin with whom she conducted fieldwork tended to idealize the Turks and Arabs living in Turkey and the Middle East and distanced themselves from the Turks and Arabs living in Berlin, who they viewed as ignorant and uneducated. The youth in MJD also regularly complained about the lack of higher education among the migrant Muslim population in Berlin.

20 Strassburger $(2003,217)$ briefly mentions similar experiences among youth participating in Milli Görüş, where transnational marriages also occur. In this respect, MJD is similar to other leisure and voluntary organizations, such as sports or school bands, where youth often find partners.

21 This also is the case in other world religions. The Orthodox Church, for example, considers marriage one of the seven sacraments of religion (Khuri 2001, 47). In the Koran, 
moment of tension and, in some ways, the ultimate sign of identification with the ethnic or religious social field. The importance of having a religiously motivated husband was emphasized in MJD through the assumption that a woman could more easily be persuaded to be lax in performing her religious duties than a man. It was also encouraged by the idea that a religiously devoted man would be more likely to follow an Islamic, rather than a traditional, gender role. These men were therefore believed to treat women better. ${ }^{22}$ The importance of establishing a family and finding a marriage partner who was religiously correct was emphasized at MJD meetings and in its newsletters. In one weekly group e-mail from MJD, a part of the "reform of the Family" item stated:

A healthy community consists of healthy families. In a few years you will marry, you are going to establish a family and your children will be future bearers of the message of the Prophet Muhammad. All the experiences, all the knowledge that a father and a mother have about Islamic work will be passed on to the son or daughter. That is why you should be wise about the choice of your marriage partner. ${ }^{23}$

Young men and young women were active in searching for a future spouse, and both made use of peers and extended family to initiate contact with a potential husband or wife. The young women were sometimes introduced to potential suitors through family visits, often initiated by the man and his family. These home visits took place mostly between people of the same ethnic background. In the course of the visits, the young man and woman would be left to talk for a while. I was often told that during these conversations, the woman would ask questions about his future plans, how he spends his money, his diligence in relation to religious practices, and whether his future wife would be allowed to work. The religious practice of the man in question was always interrogated in detail. For example:

one-third of the legal injunctions deal with marriage, the family, and how to properly manage and regulate these (El-Hadi 200o). Marriage is deemed a religious duty in the course of which one's religious faith should grow deeper. The contractual frame of marriage comprises rights and duties linked to the individual, family, and community life (Green and Numrich 2001).

${ }^{22}$ Yet, as I suggest later, the young women recognize that the religious men do not necessarily follow these ideals.

${ }^{23}$ Email dated 24. Dhul Hijja 1426 / January 23, 2006; my translation from the German original: "Eine gesunde Gemeinschaft, besteht aus gesunden Familien. Ihr werdet in einigen Jahren heiraten, ihr werdet eine Familie gründen und eure Kinder werden die zukünftigen Überbringer der Botschaft des Propheten Muhammad sein. Alle Erfahrungen, all das Wissen eines Vaters, einer Mutter über die islamische Arbeit wird übergehen auf den Sohn oder die Tochter. Deshalb müsst ihr weise sein bei der Wahl eures Ehepartners." 
Ines (20) told me of a situation where her family accepted a request from a suitor to visit their home. Ines did not mind that her family was making this kind of contact but emphasized to her mother that if the restaurant that the man in question owned wasn't halal, "like if he sells alcohol and the meat isn't proper," she would not marry him. The mother had responded, "but if he has a job in these days?" Ines had answered that, surely, she was not going to tell him how to do things, but that for her this was important.

Whereas for her mother economic capital was the most important factor in the choice of a marriage partner, Ines insisted that religious or symbolic capital had to prevail. In the end, their extended family told them that the man was dirty, meaning that he had been with other girls. He was not invited back, as moral behavior was "very important to her father." Thus the man turned out to be unacceptable both to her parents and to Ines, as his reputation within the ethnic social network was tainted due to unacceptable moral conduct. This shows the continuously overlapping perceptions of values between religious and ethnic social fields.

Ines's story demonstrates how the ethnic social field continues to be important in the process of finding a suitable spouse, both as a social space to search for a husband or wife and as a source of information concerning the reputation of the suitor or potential wife. Before the woman or man decides on engagement, the family interrogates their social network, not only in Berlin but also transnationally, about the reputation of the man (or woman). This practice became clear to me through the following discussion:

Aishegül (31) told me that she was worried that a future marriage was going to be difficult for a friend of hers, Kiraz (24). Kiraz lived in Berlin and had been engaged to a Turkish man in Istanbul, but she then broke the engagement. Aishegül was afraid Kiraz would consequently face difficulties finding a new suitor. When I suggest that if the next suitor lived in Germany he would not know about Kiraz's past engagement in Istanbul, she responded, "well, if it is with a Turkish person [in Germany], then they will ask around and then they will find out." In the end, Kiraz married a good friend of her sister's husband, someone who was not Turkish.

Reputation flows across borders, linked through the ethnic social field. Moreover, Kiraz's marriage is one example of the statistically low but increasingly common occurrence of mixed marriages among Muslims in Germany. ${ }^{24}$ The increase of multicultural marriages is partly a

24 According to von Below and Karakoyun $(2007,46)$ three-fourths of Turkish Muslims in Germany marry a Turkish partner. In comparison, half of the Italians in Germany marry ethnic Germans. 
consequence of the focus on a universal Islam detached from an ethnic group, where a future partner's religious knowledge is considered more important than his or her ethnic belonging, and partly because many meet their future partners in MJD, which is inter-ethnic.

Moreover, just as religious knowledge and the ability to articulate that knowledge becomes a symbolic capital and social competence, a religiously devoted and knowledgeable husband can also represent a form of symbolic capital. This is particularly so within MJD and the larger religious field, where religious devotion and knowledge represents a means through which one can gain respect, acknowledgement, and authority. In MJD, knowledge and performance of the pure Islam represents cultural capital. It is an embodied disposition, including skills learned within the religious social field. This cultural capital can be converted into symbolic capital, in that religious knowledge, displays of piety, the use of Islamic terms in daily conversations, and religious skills are acknowledged and recognized within the religious social field. ${ }^{25}$

Symbolic capital is about accumulated distinction and prestige and exists only as far as it is recognized in the eyes of others. It depends upon Muslim youths' capacity to distinguish between what is considered good or correct and what is viewed as bad or incorrect within this social field (see Bourdieu 1990). These youth, however, must know how to convey this knowledge discreetly; although displaying piety openly is part of demonstrating authenticity, to talk about it openly demonstrates a lack of authenticity. In order for cultural capital (in this case, religious knowledge and skills) to become and remain a symbolic capital, it must be played out with care, as it is not considered good practice to boast about one's husband or one's own knowledge and abilities in reading the Koran. Modesty must prevail. This became clear to me as a German convert, Aysel (20), used to talk extensively about the religious excellence of her husband who was a hafiz (he knows the Koran by heart) and how he was teaching her.

${ }^{25}$ Symbolic capital is "a credit, it is the power granted to those who have obtained sufficient recognition to be in a position to impose recognition" (Bourdieu 1990, 135). I have classified the acquisition of religious knowledge as cultural capital rather than religious capital. This is because the process strongly resembles that of an educational process and includes acquiring technical knowledge, skills, verbal facility, body movements, and aesthetic preferences or taste. For example, some youth attended summer courses in Egypt (or in Berliner mosques) to improve their Arabic skills and also took weekend seminars on religious topics, which also offered course certificates. The power of religious capital lies in how it represents a form of objective dispossession through constituting a laity (the people of a religious faith, as distinguished from its clergy), who by definition are those without, yet desiring, the resources that are controlled by specialists (Bourdieu 1991). 
One of the older women commented that what Aysel was doing was wrong and that she had tried to tell Aysel that she should not boast about this, since she believed that it caused other MJD participants to react negatively toward Aysel.

Participating in a youth organization that promotes multiculturalism also changes how the young people perceive other ethnic groups. One married woman, Fatima (31), recounted that "MJ made me multiculti." She felt that she learned to be tolerant as she interacted with people from different ethnic backgrounds. When she was younger, she had always been sure that she would marry a Turk, but then she ended up marrying an Egyptian. Similarly, a young Kurdish woman also told me that participating in MJD shaped her thoughts about life:

When I asked her for an example of how MJD changed her life, she said that it had changed how she thought about her future marriage partner. She used to think that it was important that her future husband be beautiful, but now she had realized that in the long run, his character and his practice of Islam were more important. She added that "there is so much crap out there." She told me that she had always practiced Islam, but not "as strict" as since she started in MJD.

Her participation in MJD had clearly shaped her worldview, including transforming her ideas of what a good husband was. ${ }^{26}$ Marriages outside of the ethnic group of their parents often caused tensions in the MJD youths' family and ethnic social field. Older generations and the extended family were particularly skeptical toward marriages outside the ethnic group. These marriages often took place after long negotiations between the youths and their parents. ${ }^{27}$ For the youth, stressing the importance of selecting a religiously oriented man as a future husband may be a request

${ }^{26}$ Age and experience may, of course, also have an impact on changes in ideas about a future marriage partner.

${ }^{27}$ It should be noted that some of the MJD participants are themselves children of mixed marriages. The group attracts people whose ethnic identification is possibly relatively weak compared to other youths who choose an ethnically homogeneous religious organization. Strassburger $(2003,218)$ refers to a survey among Turkish youth in Germany (15-24 years old) about whether the youth would consider marrying someone of a different religion. According to Strassburger, the survey indicates that religion is statistically insignificant for inter-ethnic marriage behavior. However, she does not address the level of religiosity among the youth answering the survey. Furthermore, 29 percent of the respondents answered that they "think it necessary that their own parents accept the marriage" (ibid.), which leaves open the question of whether their parents' generation is ready to accept inter-religious marriages. I also find it important to reflect on the fact that several of the married women in their late 20 s told me that when they were younger, they never thought that they would marry inter-ethnically and that this only changed after they grew older and through participating in MJD, which presented them with a multi-cultural space. 
for cultural homogeneity: because religion is such an important feature in their lives and to how they identify, many seek a partner with similar values, habits, and practices. It may also be a matter of personal qualities that they believe a religiously devoted man will possess; for example, that a Good Muslim man will be an attentive husband. Additionally, the role of education is particularly relevant: the preferable future husband should be an educated man, as he then will be more likely to represent what these youths consider a Good Muslim Man.

A mixed marriage can detach the young women further from their ethnic group, both emotionally and in terms of their social network. Fatima (31) suggested as much:

Sitting in a café in Kreuzberg, I told Fatima that I was interested in MJD in part because it has participants with different backgrounds, and she exclaimed, "multicultural! Yes, and you know that is quite exceptional. You don't find that, for example, if you go to the Turkish mosques. There they only keep to themselves. They don't want to have contact with others. (...) Like with me and my husband [she is married to an Egyptian man] — many say that it's good that we have married and that they respect that and such, but we don't find friends. Like the Turkish men can't talk with him in Turkish, and they don't like to speak German. You know, when I got married, this man who I grew up with and went to school with and had been in the mosque with, called me and said that he hoped that I had thought about it all carefully [marrying someone not Turkish], that they are so and so (...) and that you never know with the Egyptians. Can you imagine? I told him that I am 27 years old and can think about these matters fine, yes, thank you. Ah yes, he called us 'cause we had asked to have the wedding in the mosque."

Language was also an important factor in the choice of a husband. I frequently heard that the youths' parents would prefer that their future son-in-law speak their language, as their German skills were often limited. Yet, for the youths who were born and socialized in Germany, and whose religious social field takes place in German, fluency in German was more relevant than Turkish or Arabic. Fatima pointed to how language was a barrier for their social interaction with people in her ethnic social field, as in her experience Turkish men prefer to speak Turkish. Her comments are also indicative of the stereotypes that exist between the various ethnic groups in Berlin, although all of them are Muslim.

One opportunity that young people have available to them to find a future husband is what might be called "halal dating," where a couple can date with a view to marriage and do so in a religiously correct way. The tension between religious norms and the inter-gender socialization process is most often resolved by involving a sister or a trusted friend on the 
date. New technology can also create an acceptable and religiously correct space where people can get to know someone of the opposite gender. E-mail, MSN, and Skype with webcam have made it possible to create more intimate conversations, where the two young people can interact with each other in a more private setting while still upholding the religious norm of not physically being in the same space without supervision before marriage. $^{28}$

\section{Female Emancipation through Religion?}

By situating their defense of Islam in a critique of tradition, and by insisting on the privileged position of women in Islam and the particular roles of men and women in Islam, the young women try to (re)negotiate the perception of Islam both among other Muslims and among the often stigmatizing non-Muslim, German public. It is by now a normal practice that women from MJD and mosque organizations like DMK give lectures on religious themes to mixed congregations. ${ }^{29}$ Women were also active contributors to the monthly newsletter and organize meetings, seminars, and social events (such as religious celebrations, picnics, and trips abroad). Muslim women are entering and engaging in the administration of religious organizational structures and are educating themselves to be proficient speakers on Islam. In general, women have obtained new roles in the organizing and teaching of Islam in several European countries. ${ }^{30}$

Ironically, the headscarf debate has done much to allow Muslim women to develop expertise as public speakers on/for Islam in the German public sphere. Muslim women have taken on new functions as they speak in the

28 One active webcam user told me that she was not really sure whether or not this is strictly correct but felt that as long as the intention is to get married, which it was for her, she thought this would be sufficiently correct.

29 The fact that female experts present in mixed congregations is nevertheless a practice which is not frequent among Muslims in Germany. In most Islamic organizations, including MJD, female experts are only allowed to lead women's congregations.

30 Scholars (e.g. Ahlberg 1990) have pointed to a general exclusion of women from Islamic organizations and argue that the women are not treated as equal to men. Other studies, however, have found that women are increasingly making their own spaces and becoming more engaged both publicly and privately in the organization of mosques. These studies also find that women are activists, da'wa initiators, and teachers (Bendixsen 2oogb; Göle 1996; Jacobsen 2011; Jonker 2003; Jouili 2009; Spielhaus and Färber 2006). According to recent research on mosque organizations in Berlin (Spielhaus and Färber 2006), activities for girls and women's involvement in communal activities have increased from the late 1990s to 2006. Similar processes were found in Norway, where studies show an increase in women's involvement during the 1990s (Vogt 2000). 
media or on the radio, organize events, give lectures, and participate in podium discussions. Religious authorities such as Tariq Ramadan also advocate for the increased visibility of women in organizations. Consequently, many religious organizations use female spokespeople, which may well increase their credibility on gender questions in general and in the headscarf debate in particular. The representation and public involvement of women can be understood as an attempt to counteract negative images of Muslim men oppressing women within religious congregations and in their homes. Additionally, many of the young MJD participants believed they had a serious responsibility to provide role models for other young Muslims. The fact that women like them demonstrably possess organizational expertise and experience in presenting religious and political themes can encourage and give self-confidence to other women that they can also become involved and have an impact on their religious communities.

By increasing their religious knowledge, by behaving religiously correctly, and by cultivating more religiously observant friends, young women can gain social capital and a way out of parental surveillance and control while also avoiding criticism that they have become too German. As such, identification with Islam can, perhaps paradoxically, lead to an increased emancipation from their families. Research on Muslim youths has indicated that young people, and particularly young women, have the option of drawing on religious arguments to counter constraints from their families and ethnic groups. ${ }^{31}$ This gives Muslim women a way to avoid traditional customs, such as forced marriage or withdrawal from the public sphere, without damaging the family relationship. In Berlin, I noticed that increased knowledge of Islam could provide youth with self-confidence and a legitimate foundation from which to challenge some of the restrictive attitudes held by the older generation. By reading the Koran and familiarizing themselves with the rules and rights within Islam, the youth empowered themselves. When their parents tried to restrict their actions on the basis of Islam, the girls and young women could "talk back" or challenge parental prohibitions by referring to Islam and the Koran. Aishegül (31) made me aware of this. She was unmarried, lived at home, and studied at university. She had joined MJD a few years previously, and started to wear the headscarf and to pray regularly. Her parents used to not allow her to take part in extra-curricular activities. Aishegül said:

31 See in particular Ali (1992), Dwyer (2000), Jacobson (1998), Nökel (2006), Salih (2003) Shaw (1988), Roy (2004). 


\begin{abstract}
"Now I can do whatever I want, and they won't say no." Being quite familiar with the Koran and its content, she now also argued with her parents. If they claimed that a particular action was not in accordance with Islam, she would ask: "Where does it say that?" She continued, "and you know, being in the Muslim group made me know more about my real rights [according to Islam]. Attending Islamic education actually emancipated me. I started to know my rights, and that Islam should not be taught at home, but in a community and that it is my right to receive Islamic education. At first, I asked my parents if I could go (and sometimes I had to argue with them), and then I just started to say, 'I'm going here and there,' without asking permission, 'cause it is my right. Now I could go to Indonesia, if I wanted to. Now they really want me to finish my [university] degree. It is their only concern right now."
\end{abstract}

Islam can offer a way out of their ethnic social field, and women can try to subvert men's intentions by taking on a religious rhetoric that is detached from culture. Here, Aishegül suggests how in some instances, MJD can feel like a free space compared to that of the family. The clear distinction that is made between culture and religion breaks down hierarchies of knowledge, since individuals can wield book-knowledge and sources of authority that are necessary for legitimate arguments inside the group. This approach to Islam, together with enhanced education and knowledge of Islam, makes it possible for young women to de-legitimize their parents' positions by saying that these are based on culture. To some extent, it leads to a crisis in their parents' authority: the youth do not discuss religious matters extensively or solely with their parents. Instead, they feel that they know more about Islam than their parents and can call upon a greater Islamic knowledge and higher moral authority. ${ }^{32}$ Sometimes the young women attempted to shape their own mothers' practices, such as inducing them to veil, and they judged their parents for their lax religious lifestyles. In consequence, the age hierarchy can be overturned, and to some extent the youth can become the religious educators of their parents. This perspective can be seen as an alternative to the oft-cited idea that Islam only creates limitations for women and that Islam is a tool for parents to control their daughters. As such, the focus on the emancipatory aspects of Islam is an important consideration for those women who seek to evade strict controls legitimized as Islamic by their parents

32 The breakdown of parents' authority and increased freedom of movement for young Muslim women as a result of turning to a pure Islam have been suggested by a variety of scholars who disagree on other issues: Amiraux (2001), Brenner (1996), Dwyer (2000), Jacobsen (2011), Jouili (2009), Khosrokhavar (1997, 144), Mahmood (2005, 116), Nökel (2002), Roy (2004), Salih (2003), Weibel (2000). 
but delegitimized as unreligious and traditional by the girls and young women.

\section{Reconfiguration of Authority}

However, even if I agree with the argument that a young person's orientation toward Islam can lead to some degree of emancipation or freedom of movement, my fieldwork indicates that this is by no means absolute. During fieldwork, I realized that the parents' authority was often reemphasized through Islamic discourses. During presentations, the youths' obligations and duties as daughters or sons and the significant role and position of parents within Islam were frequently stressed. It was considered a great sin to break with one's family, and the young people avoided doing so to the extent possible. The following discussion, which took place during the annual MJD regional meeting in a mosque in Wedding, illustrates this well:

MJD members from outside Berlin were participating in a one-day event with presentations and social activities organized by MJD Berlin. The attendees included about 40 young women and 30 young men from Berlin, Bremen, and Cologne. After a presentation by a young, newly trained imam, the listeners could ask questions. A woman of about 30 years asked: "What about the parents..., if you feel that your parents are too strict, like really too much, how should you react?" The young imam answered: "Sometimes there are questions to which I feel like saying that it depends on the situation, and this is such a question. Allah has told us that after him come the parents. And it's like that, nothing we can do about that. If your parents are doing $d u^{\prime} a$ for you, that is a blessing, that is the best. If your parents throw you out [that is very bad]." He went on to say that Allah gave them something else at the same time, which is that if there is something that goes against His wishes, then one should not do it. He continued, "but parents are sometimes very strict, we know that. But they have lived longer, have more experience, they have seen things. We are modern - we know how it is to live in this society. But we don't always know the right thing to do. We have to think about this also." He added that if they were sure that their parents were wrong, "then you have to find a way to tell them that. Like, not in a stressful situation, then you will get nowhere. Like, it is the same with your boss at work-don't ask for something when he is in a bad mood. After all, you have a goal, and try to achieve that when they are in a good mood. Ask when you see that it is a good moment, then start to talk about it (...)."

A young convert put her hand up and continued the discussion: "But how should you react when your parents are not Muslims but the opposite, and they are saying things against your headscarf and such?" The young imam answered: "One should still respect one's parents and treat them very kindly. But not go against Allah." Another woman insisted, "but what if your parents 
are making you do things, like forced marriage?" He answered patiently, "as I said, parents should not make you do things which are against Allah's will. And in Islam, it is very clear, forced marriage is not allowed! But one has to be wise, and find a wise solution to the problem. It is important to find people that you respect, and people your parents respect; like that you can find a solution. One of the greatest sins, mortal sins, is (to break) with your parents. It's not recommended! There is always a solution to a problem. The wiser one is, the wiser solution one can find." After the question round finished, one of the MJD brothers came forward and said, "I want to end the meeting with a story. A woman comes to the mosque and tells the imam that she wants her daughter to become Muslim. The imam is surprised and asks her why. Is she herself a Muslim? No, but our neighbors are Muslims and I see how well they treat their parents [i.e. she also wants her daughter to treat her like that]. The imam asks, and what about you? She answers: 'My mother is already dead!" The assembled members laughed. ${ }^{33}$

I noticed that only women asked questions during this discussion, suggesting that these themes might be more imperative for young women in their roles as Muslim daughters compared to young men. The young women need to find a path between what they see as their Islamic duty to remain respectful toward their parents and the imperative to follow what is correct according to Islam. This can lead to moments of tension where what is considered the right answer is not clear-cut. Young women can employ religious arguments in their discussions with their parents, but at the same time, the respect and authority that Islam gives to their parents create limits to this emancipation process. Islamic teaching frequently emphasizes the parents' role and position in Islam. Being a good daughter includes respecting one's parents, their needs, and their knowledge. For example, during an MJD meeting Fadwa contended that "each one of us is so fortunate because we have received the best parents." Another principle often mentioned is that "the best Muslim is the one who takes proper care of their family." It is an important part of Islamic family law, even if it is not tied to any specific legal injunction (Roald 2001). Thus, when young people's knowledge of Islam increases, this does not subvert the authority of the family, but it does restructure it. The family's authority is reinstated through the youth's religiosity. ${ }^{34}$

33 The joke is also available at www.youngmuslims.ca/articles/display.asp? $\mathrm{ID}=73$, accessed January 20, 2007.

34 In Protestantism it finds its equivalence in the words of Jesus: "Leave your family, leave your friends, leave your home, and join me." This can also be understood within the framework of Alberoni's (1984) research on movements. He contends that any movement creates ethical dilemmas for its members and that each person must show to themself and to others that they are a member of the group in order to become part of the movement. 
Furthermore, even if the young people themselves understand gender roles in a religious way and try, to a greater or lesser degree, to follow this in their daily lives, this does not stop them from facing social expectations that they personally believe are solely ethnically or culturally based. Although the youth themselves turn to what they believe is a true Islam, their parents and traditionally or culturally oriented Muslims do not necessarily share this understanding of Islam. This means that the youth must mediate between different religious and cultural frames of reference, ideals, and values. Social practices and restrictions considered traditionally or culturally defined continue to be asserted and sometimes prevail. For example, the father of one eighteen-year-old MJD participant did not allow her to move outside Berlin in order to pursue her university degree. Additionally, at one point Ines (20) explained that she did not want to visit the doctor until she was married because there was always someone who would see her and who might start talking about "why she is there." She was worried about the gossip that might damage her reputation, even though she was not behaving religiously incorrectly by visiting the doctor while not married. This calls to mind the community policing (Dwyer 2000,479 ) that I discussed in chapter 3.

In this representative role the women did accept limitations on the subjects they could speak about, as many considered it necessary to focus on how Islam empowered their lives. It can be difficult for women to be critical of their own group, as their agency becomes oriented toward "defending" their group and their men. It is my impression that both women and men show a strong preference for arguments or struggles against the continued gender discrimination within different Muslim congregations to take place in the private sphere, away from the (critical) gaze of non-Muslims. ${ }^{35}$

Although a religiously defined gender order may provide the youth with more space for negotiation than culturally defined gender norms, women

\footnotetext{
This includes leaving behind old ideas and fidelities: "leave everything and come with me"; "leave your father and mother and join us." At the same time, such dilemmas are expressed in a form of double bind: "leave your father and mother" and at the same time the instruction to "honor father and mother" (Alberoni 1984).

35 The role of women in different Muslim organizations in Berlin varies. In one mosque, some women decided to make their own women-only religious community "because the men only created problems." Others complained about male dominance when working in certain mosque organizations (outside MJD). However, the solution these Muslim youth proposed to improve this situation was not that the men should become more German but that they should become more educated, and especially become more educated about Islam.
} 
are not able to decide on legitimate interpretations of religious rules and texts. As discussed in chapter 5 , the youths are not free to define what a Good Muslim Woman is and cannot freely choose the actions that are legitimated within the religious discourse. In fact, women seldom participate in the authoritative interpretation of the rules and texts. ${ }^{36}$ Overall, women have limited access to or ability to participate in pivotal discussions about religious interpretations. These discussions are generally controlled by men. In consequence, women's experiences and interests are easily omitted. This gender-divided social space in the religious field points to the different sources of information available to men and women. ${ }^{37}$ The physical and spiritual gender separation may lead to men and women not adequately sharing knowledge of each other's experiences and to a situation where women receive insufficient information and where there is little room for their opinions. Effectively, there is a risk, intended or unintended, that male privilege and male interpretations are (re)produced.

Different discourses on what pure Islam is generate conditions for the social space within which these youths operate. This space becomes especially tense in view of the fact that the correct construction of the gender order is itself the subject of much disagreement and discussion about values and attitudes among Islamic organizations. Although there was a balanced gender representation in MJD activities and five of the ten members in the shura (religious council) were women (in 2008), the national leadership (the Vorsitzende or Amir) of MJD has since its founding been male. There are still religious situations where gender remains a crucial category. For example, women cannot lead the prayer in mixed congregations, and the women must pray behind the men, sometimes in a separate room. ${ }^{38}$ There were generally no discussions about gendered prayer spaces and ritual performances, and these were accepted as given by Islam.

36 It is not my impression that the young women I worked with were specifically pursuing a so-called Muslim feminist position. For a discussion on the usefulness of the concept of "Islamic feminism," see Mir-Hosseini (2006) and Moghadam (2002). Moghadam, focusing on Iran, contributes to a general understanding of the potentiality and limitation of Islamic feminism.

37 Anne Sofie Roald contends that "this segregation is not always visible, but even when men and women are present in the same room there will be an invisible barrier due to a strong idea of segregation inhibiting interaction between the sexes. The result is that men and women have access to different information" (Roald 2001, 76).

38 In several mosques, women listen to the prayer and religious presentation (khutba) via a loudspeaker system or a television feed from the men's section. In conservative theology, a woman's voice is considered erotic and is thus not suitable to hear, especially in ritual contexts. 
In sum, there were situations where the young women's religious knowledge might not represent a symbolic capital; in particular, the structure and production of religious knowledge formation continues to be largely male-dominated. ${ }^{39}$ A woman's religious knowledge thus only increases her symbolic capital in certain restricted areas, such as when talking to other women and when choosing a marriage partner.

\section{An Alternative Space}

I see the set of dispositions, knowledge, and forms of behavior that the young women acquire through acting within this religious faith community as representing the acquisition of a (new) religious habitus and bodily hexis-a way of comporting their bodies. The clear distinction that the youths made between culture and tradition on the one hand, and religion on the other, made it possible for them to not feel betwixt and between their parents' home country and Germany. One of the original MJD initiators, Fatima (31), said that:

"Religion can be a bridge (because it combines both). One can say 'I am a Muslim' and it does not matter whether one is German, Turkish, or Arabic." She explained that since their parents are Muslims, even if they are not necessarily religiously active, the utterance "I am a Muslim" would be accepted.

Fatima's comment exemplifies how identifying foremost with religion can form a space for youth who otherwise must struggle between their parents' expectations that they be Turkish or Arabic and those of their peers or teachers who do not consider them German. Moreover, through becoming skilled at and gaining knowledge of what constitutes correct knowledge and how that knowledge is validated (as discussed in chapter 4), as well as about correct dress and body comportment defined by a religious gender order, the youth are crafting a religiously gendered, deethnicized Self in Germany. Separating tradition and culture from religion enables the young women to dismiss certain gendered expectations on their behavior as cultural. Simultaneously, although there are individual

39 See Jonker (2003) for a discussion about the increase in women's spaces within mosques and the entrance of more women with religious education, which she argues in the long run may shape religious knowledge formation generally. Jonker argues that the production of knowledge among Muslims in Germany is still structurally connected to an overall male core. At the same time, she shows that there are Muslim women who produce knowledge in "external production sites" (Jonker 2003, 37), outside the domination of male authority. 
responses and internal disagreements, the religious field (like any social field) imposes specific kinds of efforts or struggles on them as actors.

Constructing and encouraging a Muslim identity detached from ethnic or national identity may well be an effort to achieve recognition for Islam as a religion at home in Germany, and for Muslims as not migrants, but German citizens. In the long run, it is likely that Islam and Muslims will be more accepted in German society if Islam is viewed as practiced by individuals who identify and are viewed as citizens of Germany. To some extent, then, MJD and its work represent an identity movement that seeks to create or underline a social and cultural identity of a group (or category) in order to change this group's status in society. Islam provides a glue between them and their friends; one that many are seeking to investigate further. The religious sphere offers a way out of the ethnic social field without seeking to be embraced by the non-Muslim, German social field. Yet following a pure Islam represents an alternative universality through which the youth maintain the position of the Other. 